\title{
ENDEREÇAMENTO NAS PROPOSTAS DE PRODUÇÃO TEXTUAL EM LIVRO DIDÁTICO DO ENSINO FUNDAMENTAL
}

FABIANA KAODOINSKI*

Flávia Brocchetto RAMOS**

\section{RESUMO}

O presente estudo visa a analisar como propostas de produção textual veiculadas em livro didático do Ensino Fundamental situam o estudante em termos de interlocução, observando se esse material tem a preocupação de caracterizar o provável interlocutor da escrita a ser elaborada pelo aluno. Para tanto, tomou-se como base a teoria dialógica de Bakhtin, adotando-se a perspectiva enunciativo-discursiva de linguagem. Optou-se pela análise de propostas de produção textual presentes na coleção Português: Linguagens, dos autores Willian Roberto Cereja e Thereza Cochar Magalhães. A partir do corpus analisado, observou-se que as referidas propostas não apresentam caracterização detalhada do possível interlocutor, não contemplando plenamente a noção bakhtiniana de endereçamento. Assim, em função de elas não explicitarem quem é o outro do discurso, a escrita produzida pelo estudante pode, além de tornar-se artificial, não favorecer o estabelecimento de um ativo e efetivo diálogo entre os interactantes.

PALAVRAS-CHAVE: Endereçamento, produção textual, livro didático.

\section{INTRODUÇÃO}

Sabe-se, por meio de pesquisas, como a realizada pelo Instituto Paulo Montenegro - por meio do Indicador de Analfabetismo Funcional $\left(\right.$ INAF $^{1}{ }^{-}$, que parcela significativa da população brasileira possui

* Doutoranda em Letras pela Universidade de Caxias do Sul (UCS). Mestra em Educação e Licenciada em Letras pela Universidade de Caxias do Sul (UCS), Caxias do Sul, Rio Grande do Sul, Brasil. E-mail: fabikafabi@gmail.com.

** Doutora e Mestra em Letras pela Pontifícia Universidade Católica do Rio Grande do Sul (PUCRS), Porto Alegre, Rio Grande do Sul, Brasil. Professora Adjunta da Universidade de Caxias do Sul (UCS), Caxias do Sul, Rio Grande do Sul, Brasil. E-mail: ramos.fb@gmail.com. 
carências quanto ao desenvolvimento de habilidades de leitura e de escrita. No que se refere aos egressos do Ensino Médio, o INAF 20112012 apontou que somente $35 \%$ deles são considerados plenamente alfabetizados.

Esses resultados suscitam reflexão sobre o papel da educação formal no que se refere à modificação dessa realidade, já que os professores das diferentes áreas do saber - principalmente os da disciplina de língua materna -, utilizando variados recursos, podem promover situações de aprendizagem com as quais os alunos consigam aprimorar habilidades, de forma que tenham condições de compreender e de produzir diversos enunciados/discursos. Nessa perspectiva, acreditase que, com a ampliação da competência linguística dos estudantes, é possível haver uma mudança nos índices negativos de desempenho nas práticas de escrita.

Como o livro didático é um dos recursos presentes nas práticas escolares, participando, portanto, do processo de letramento e sendo, muitas vezes, o material impresso básico para o ensino, acredita-se que, se ele conseguir mostrar-se um promotor de práticas de escrita que simulem um contexto real de uso da língua, pode ser uma ferramenta para a melhoria da qualidade do ensino. Sendo assim, parece ser pertinente que esse material seja avaliado.

No Brasil, várias pesquisas, com diferentes perspectivas - de diversos autores, como Costa Val, Castranheira, Batista, Reinaldo, Rojo, Buzen, Marcuschi, Freitag, Rangel, Dionísio, Bezerra -, tiveram ou têm como objeto de estudo os livros didáticos. Algumas problematizam a forma como, neles, é solicitada a produção de textos, sendo que resultados de diversas investigações convergem para a noção de que, geralmente, esses manuais apresentam propostas de escrita com pouca clareza a respeito das condições de produção do discurso. Isso pode ser explicado, porque, segundo Marcuschi (2003), nos livros didáticos, predominam análises formais e estruturais, sendo que, geralmente, as atividades de escrita são superficiais, realizadas para que o professor atribua uma nota.

Nesse sentido, destaca-se a consideração de Reinaldo (2006, p. 275) de que "essa prática contribui para as já conhecidas dificuldades de tomadas de decisão do aluno produtor, em termos de planejamento e gestão do texto". 
Levando em conta essas questões, parte-se da hipótese de que o fato de o livro didático nem sempre propiciar ao estudante uma descrição clara da situação de produção do discurso, principalmente caracterizando o interlocutor, interfere no estabelecimento do diálogo necessário a essa prática e, portanto, na qualidade da escrita e na motivação do aluno quanto à realização da atividade.

Nessa perspectiva, o presente estudo tem como objetivo analisar o modo como as propostas de produção textual em um livro didáticos do Ensino Fundamental situam o aluno em termos de interlocução. Ou seja, almeja-se observar se o livro didático em análise tem a preocupação de caracterizar o provável interlocutor da escrita produzida pelo estudante, o que permite verificar se a noção bakhtiniana de endereçamento - traço essencial, constitutivo e determinante para a construção do discurso é contemplada no material didático. Entende-se que a caracterização do interlocutor nas propostas de produção revela a preocupação dos autores dos livros de propiciar situações enunciativas que contribuam para o discente produzir enunciados e discursos mais significativos, relacionados à sua realidade e/ou necessidade, o que parece contribuir para o desenvolvimento de habilidades de escrita.

Posto isso, na seção 1, apresenta-se uma reflexão sobre a teoria dialógica, explicitando-se os conceitos de linguagem, enunciado, gênero e endereçamento, os quais sustentam e embasam as análises e discussões apresentadas a seguir. $\mathrm{Na}$ seção 2, mostra-se o corpus a ser analisado, nesse caso a coleção Português: Linguagens, dos autores Willian Roberto Cereja e Thereza Cochar Magalhães (2012). Além de justificar a escolha, delimita-se, de modo mais contundente, o percurso de análise a ser seguido no estudo. Na seção 3, finalmente, são discutidos os resultados da pesquisa, por meio da análise do tratamento que os autores da coleção didática dispensam à questão da interlocução em suas propostas de produção textual.

\section{Pressupostos teóricos}

\subsection{A TEORIA DIALÓGICA}

Elaborada pelo Círculo de Bakhtin², a abordagem dialógica da linguagem se propõe a compreender a linguagem e seu funcionamento, 
assim como discute a constituição dos gêneros discursivos, levando em conta sua relação com a situação de interação, realizada no meio social, nas esferas de atividade humana. Para esclarecer o conceito de dialogismo, será explanado, primeiramente, o que se entende por diálogo no âmbito discursivo.

Para Mikhail Bakhtin $(1981)^{3}$, que viveu no período compreendido entre os anos 1895-1975, o diálogo é caracterizado pela alternância dos sujeitos no discurso, sendo que a palavra é dirigida por um locutor a um interlocutor, os quais ocupam posição social. Nesse sentido, a palavra se constitui como uma "ponte" do primeiro para o segundo e vice-versa. Por meio dela, o sujeito se define em relação ao outro. Para o autor, o diálogo é uma das mais importantes formas da interação verbal, pois contempla toda a comunicação verbal. Nesse sentido, o enunciado caracteriza-se também como dialógico por estar sempre inter-relacionado com outros enunciados: não existe enunciado isolado, pois há sempre um outro que o antecede e outros que o sucedem.

Bakhtin $(2003)^{4}$ afirma que, na comunicação discursiva real há dois parceiros, sendo que o ouvinte (interlocutor) não é passivo; pelo contrário, percebe e compreende o significado do discurso, agindo de forma responsiva em relação ao locutor, ou seja, "concorda ou discorda dele (total ou parcialmente), completa-o, aplica-o, prepara-se para usálo, etc" (BAKHTIN, 2003, p. 270). Assim, mesmo que a expressão seja uma criação individual, ela é exterior, pois está direcionada ao meio social, gerando possibilidades de reações e réplicas; conquistando o apoio do outro ou estando exposta à rejeição.

Cabe ressaltar que, sendo considerado um "ato de fala impresso", o livro também se configura como "objeto de discussões ativas sob a forma de diálogo" (BAKHTIN, 1981, p. 124). Desse modo, o interlocutor tem a possibilidade de relacionar-se ativamente com o material escrito, comentando e criticando passagens, por exemplo. Portanto, o livro didático também se mostra um elemento da comunicação verbal, a qual, para Bakhtin (1981, p. 124), "entrelaça-se inextricavelmente aos outros tipos de comunicação e cresce com eles sobre o terreno comum da situação de produção".

Para ampliar o entendimento sobre a teoria dialógica, serão explorados a seguir alguns conceitos básicos a partir dos quais ela estabelece suas bases. Entre eles estão as concepções de língua e de linguagem, de enunciado, de gêneros do discurso e de endereçamento. 


\subsubsection{LinguAGEM}

Nos estudos realizados pelo Círculo bakhtiniano, os termos linguagem e língua não apresentam uma definição linear, uma vez que tais noções emergem em diversos textos, de diferentes épocas e pela voz de diferentes autores do grupo. Para a compreensão da concepção de linguagem em Bakhtin e no Círculo, é necessário, portanto, articular leituras diversas, não só do autor como de seu grupo.

Para o Círculo, toda a vida social é permeada pela linguagem, a qual atua na formação da sociedade e da política e ainda nos sistemas de ideologia. Portanto, a linguagem não se reduz a uma concepção de enunciação monológica, nem "à expressão do pensamento, nem a um sistema abstrato de formas como respectivamente a consideram" (MAGALHÃES, 2011, p. 51). Superando tais posições, a linguagem direciona-se para a tensão existente no âmbito social, verbal e ideológico, evidenciando a noção de interação verbal. Para Bakhtin (1981, p. 123), a "verdadeira substância da língua" constitui-se pela interação verbal, considerada um fenômeno social.

A concepção compatível com a perspectiva dos autores do Círculo é aquela que possui caráter histórico, social e ideológico, em que o gênero se efetiva em uma situação de interação social, uma vez que sua constituição é firmada na relação estabelecida entre o locutor e o interlocutor pela interação. Enfim, a linguagem é concebida por Bakhtin (1981, p. 125) como "uma criação coletiva integrante de um diálogo cumulativo entre o eu e o outro, entre muitos eus e muitos outros". Nas palavras de Magalhães (2011, p. 53), "a noção de dialogismo é a que melhor resume e sustenta a teoria bakhtiniana".

\subsubsection{ENUNCIADO}

Bakhtin (2003, p. 269) argumenta que a heterogeneidade de gêneros do discurso dificulta a elaboração de uma definição sobre a natureza geral do enunciado, o qual é entendido como a "unidade real da comunicação discursiva”. Segundo o referido autor (2003, p. 261), "o emprego da língua se efetua por meio de enunciados, concretos e únicos, os quais têm relação com 'as condições específicas e as finalidades de cada campo da atividade do homem"'. As enunciações ${ }^{5}$ concretas dos sujeitos geram o discurso, e "cada enunciado particular é individual, mas cada campo de utilização da língua elabora seus tipos 
relativamente estáveis de enunciados, os quais denominamos gêneros do discurso" (BAKHTIN, 2003, p. 262).

Segundo Bakhtin (2003), a língua efetiva-se em forma de enunciados, os quais não estão situados no nível do sistema linguístico, mas no nível das relações de sentido, ou seja, no nível do discurso. $\mathrm{O}$ enunciado é a unidade concreta e real da comunicação discursiva, dado que o discurso só pode existir na forma de enunciados concretos e singulares, pertencentes aos sujeitos discursivos de uma ou outra esfera da atividade humana. Cada enunciado é sempre novo e irrepetível, representando um novo acontecimento, uma nova postura ativa do falante dentro de uma ou outra esfera de objetos e sentidos. E, ao mesmo tempo em que é um elemento inalienável e singular, representa apenas um elo na imensa cadeia discursiva, porque não é o primeiro nem o último dessa rede: tanto responde a enunciados anteriores como antecipa outros que o seguem: "Cada enunciado é um elo na corrente complexamente organizada de outros enunciados" (BAKHTIN, 2003, p. 272).

Nesse sentido, de acordo com Brait e Melo (2005, p. 75), "um texto, um enunciado não se sustenta fora de suas esferas de circulação, produção e recepção". O enunciado precisa ser analisado em sua situação social, ou seja, em sua relação com outros enunciados, nunca isoladamente, já que um está ligado ao outro em sua relação dialógica e de sentido.

Por meio da língua, o enunciado se realiza, mas não se limita ao sistema linguístico. Em sua constituição semântica, para que seja compreendido, depende de fatores extraverbais e sociais. Dito de outro modo, ao contrário da oração e da palavra - em suas formas abstratas e sem acento de valor, as quais são dotadas de conclusibilidade gramatical -, o enunciado é marcado pela alternância dos falantes, pelo contato direto com a realidade, com a situação extraverbal. Sendo assim, como um enunciado estabelece relação com outros enunciados, há a constituição do sentido, o que provoca possibilidade de resposta. Ademais, toda enunciação gera enunciados novos e irrepetíveis (BAKHTIN, 2003).

Quanto à conclusibilidade do enunciado, pode-se dizer que a alternância dos sujeitos do discurso, considerando o ponto de vista interior do enunciado, define seu acabamento. No caso do falante, quando ele pronuncia o que deseja, faz com que seu interlocutor perceba o tom conclusivo de seu enunciado e, assim, possa, a partir da compreensão responsiva, respondê-lo. Nesse sentido, a vontade discursiva do falante é interpretada pelo interlocutor, o qual mede a conclusibilidade do enunciado (BAKHTIN, 2003). 
Além disso, por meio das formas típicas, genéricas e composicionais desse enunciado, o locutor orienta seu discurso e o interlocutor consegue fazer previsões não só do acabamento do enunciado, mas também do volume, da extensão e da atitude valorativa (MAGALHÃES, 2011). Cabe destacar que a atitude valorativa é revelada porque todo enunciado é expressivo, portanto, nunca pode ser neutro. A entonação, por exemplo, é considerada um traço constitutivo do enunciado, relacionando-o ao seu contexto. Ela representa, segundo Bakhtin (2003, p. 290), a "[...] relação emocionalmente valorativa do falante com o objeto da sua fala".

\subsubsection{GÊNERO DISCURSIVO E ENDEREÇAMENTO}

Para Bakhtin (2003, p. 262), os gêneros do discurso são "tipos relativamente estáveis de enunciados", elaborados por cada campo de utilização da língua. Essas formas típicas estruturam a totalidade discursiva e orientam a sua construção e compreensão.

A noção de gênero discursivo de Bakhtin está associada à esfera da atividade humana - como jornalística, científica, religiosa - e relacionase à concepção de linguagem dialógica, estando também associada à noção de interação verbal, pois o funcionamento e a constituição dos gêneros se efetivam em situações de interação. Dependendo de como se institui essa interação, gêneros discursivos próprios podem ser criados, estabilizando-se historicamente, ou ainda ser atualizados permanentemente. Além disso, o gênero se constitui por tema, estilo e estrutura composicional. (BAKHTIN, 2003).

Os gêneros efetivam a comunicação humana e são responsáveis pela concepção e pelo julgamento que o homem tem a respeito do mundo, estando presente em cada esfera social, correspondendo às suas condições específicas. Cada esfera possui seu repertório de gêneros, sendo que à medida que ela fica mais complexa, esse conjunto em uso pode diferenciar-se. Isso ocorre porque os gêneros são concretos e históricos, havendo sempre um movimento entre sua manutenção e sua renovação em cada situação de enunciação. Para Magalhães (2011), esse movimento reflete transformações presentes na sociedade.

O gênero está associado à manifestação concreta da língua e implica pensar a interação humana e, consequentemente, o seu 
endereçamento. Na constituição do discurso, há um papel ativo dos outros, ou seja, daqueles a quem o enunciado elaborado se endereça. Nas palavras de Bakhtin (2003, p. 301), "[...] é como se todo o enunciado se construísse ao encontro dessa resposta".

Diferentemente das palavras e das orações - enquanto unidades significativas da língua -, que são impessoais, o enunciado direciona-se sempre a alguém. Esse processo foi definido por Bakhtin (2003) como endereçamento. Para o teórico (2003, p. 301), "o enunciado tem autor e destinatário", o qual pode ser uma pessoa, uma coletividade, um outro indefinido (monológico), etc.

Ocorre também, na construção do enunciado, uma definição ativa e uma busca de antecipação quanto às respostas a serem recebidas:

Ao falar, levo em conta o fundo aperceptível da percepção do meu discurso pelo destinatário: até que ponto ele está a par da situação, dispõe de conhecimentos especiais de um dado campo cultural da comunicação; levo em conta as suas concepções e convicções, os seus preconceitos (do meu ponto de vista), as suas simpatias e antipatias - tudo isso irá determinar a ativa compreensão responsiva do meu enunciado por ele (BAKHTIN, 2003, p. 302).

O locutor escolhe o gênero, os procedimentos composicionais e os meios linguísticos do enunciado. Portanto, o endereçamento diz respeito à atitude do falante/locutor em relação ao interlocutor, sendo fundamental para compreender a expressividade do enunciado. Textualmente, explica Magalhães (2011, p. 61), “[...] o enunciado, seja ele uma réplica ou um romance, possui sempre autor e destinatário e revela uma posição frente à realidade e aos outros participantes da comunicação discursiva”. Depois dessa discussão teórica, passamos à análise de aspectos do livro didático.

\section{Pressupostos metodológicos e CARACTERIZAÇÃo do OBJeto DE ESTUDO}

Nesta pesquisa, predomina abordagem qualitativa, pois a preocupação não é com a quantificação de dados, mas com a interpretação de objeto real, evidenciando seus significados. O objeto 
deste estudo, o livro didático, não é uma realidade neutra; está repleta de significações que precisam ser analisadas e desveladas para que os indivíduos da prática educativa possam desenvolver, eficientemente, diferentes habilidades. Destaca-se, também, que, mesmo sendo de conhecimento geral que o livro didático representa apenas um suporte a sofrer adaptações pelo professor, ele é utilizado em várias situações de ensino e de aprendizagem. Assim, cabe haver compatibilidade entre a perspectiva de língua defendida pelo autor do manual e as atividades por ele propostas no decorrer das propostas didáticas.

Optou-se, neste trabalho, pela análise do livro do $9^{\circ}$ ano da coleção Português: Linguagens, de William Roberto Cereja e Thereza Cochar Magalhães - Ensino Fundamental. Os autores orientam, no Manual do Professor, que o ensino de Português deve abordar a língua numa perspectiva de "[...] instrumento de comunicação, de ação e de interação social", privilegiando a "perspectiva textual e enunciativa" (CEREJA; MAGALHÃES, 2012, p. 2). No que tange à aprendizagem de gêneros discursivos, os autores asseguram que:

[...] a aprendizagem deva se dar em espiral, isto é, que os gêneros devam ser periodicamente retomados, aprofundados e ampliados, de acordo com o ano, com o grau de maturidade dos alunos, com suas habilidades linguísticas e com a área temática de seu interesse (CEREJA; MAGALHÃES, 2012, p. 12).

Essa coleção foi escolhida porque o $9^{\circ}$ ano representa etapa conclusiva do Ensino Fundamental. Ela é utilizada na rede municipal de Caxias do Sul, tendo sido selecionada pelo Plano Nacional do Livro Didático - PNLD/MEC, o qual avalia e disponibiliza gratuitamente obras didáticas voltadas à educação básica pública, a fim de qualificar os processos de ensinar e de aprender, de acordo com o disposto no Decreto $n^{\circ}$ 9.099, de 18 de julho de 2017.

Português: Linguagens, de Cereja e Magalhães (2012), é composta por 4 volumes, os quais se apresentam subdivididos em 4 unidades temáticas. No caso do volume IV da coleção, do $9^{\circ}$ ano, os temas transversais são: valores, amor, juventude e nosso tempo. Cada unidade possui 3 capítulos, havendo, entre uma unidade e outra, pequeno 
capítulo não numerado com sugestões de atividades, denominado Intervalo.

Em cada capítulo de cada unidade, há um espaço destinado a orientar a escrita do aluno, intitulado Produção de texto, dividido, normalmente, em três seções: na primeira, o estudante tem contato com um exemplo do gênero em estudo e, a partir dele, realiza atividades de leitura e de interpretação; na segunda, Agora é sua vez, é solicitada a elaboração de um texto de acordo com o gênero em questão; e em Para escrever com expressividade são apresentadas atividades gerais de linguagem.

Considerando o objetivo desta pesquisa, focar-se-á aqui na seção Agora é sua vez, verificando se as doze propostas de produção textual desse material didático situam os alunos em termos de interlocução, de acordo com a noção bakhtiniana de endereçamento. Para tanto, apurar-se-á se estão explicitadas as condições de produção do gênero discursivo a ser escrito, em especial se o interlocutor é definido e caracterizado. Em caso positivo, buscar-se-á avaliar como foi feita essa caracterização, a partir das seguintes categorias: a) a descrição do interlocutor contempla plenamente a noção bakhtiniana de endereçamento; b) a descrição do interlocutor contempla suficientemente a noção bakhtiniana de endereçamento; c) a descrição do interlocutor contempla razoavelmente a noção bakhtiniana de endereçamento; e d) a descrição do interlocutor é insuficiente para contemplar a noção bakhtiniana de endereçamento.

Por questão de objetividade do estudo, serão explicitadas apenas as propostas apresentadas no volume IV, do $9^{\circ}$ ano, por ser amostra significativa da obra em estudo.

\section{ANÁLISE E DISCUSSÃO DOS RESULTADOS}

$\mathrm{Na}$ sequência, serão explicitadas as propostas de produção textual presentes do livro em análise, em especial as partes em que se pode perceber a noção de endereçamento. Após, elas serão avaliadas conforme metodologia descrita anteriormente. 
QUADro 1 - Propostas de PRODUÇÃo TEXTUAL EM MANUAL DidÁTICO

\begin{tabular}{|c|c|}
\hline $\begin{array}{c}\text { Unidade /capítulo } \\
\text { - Gênero }\end{array}$ & Proposta de produção \\
\hline 1/1 - Reportagem & 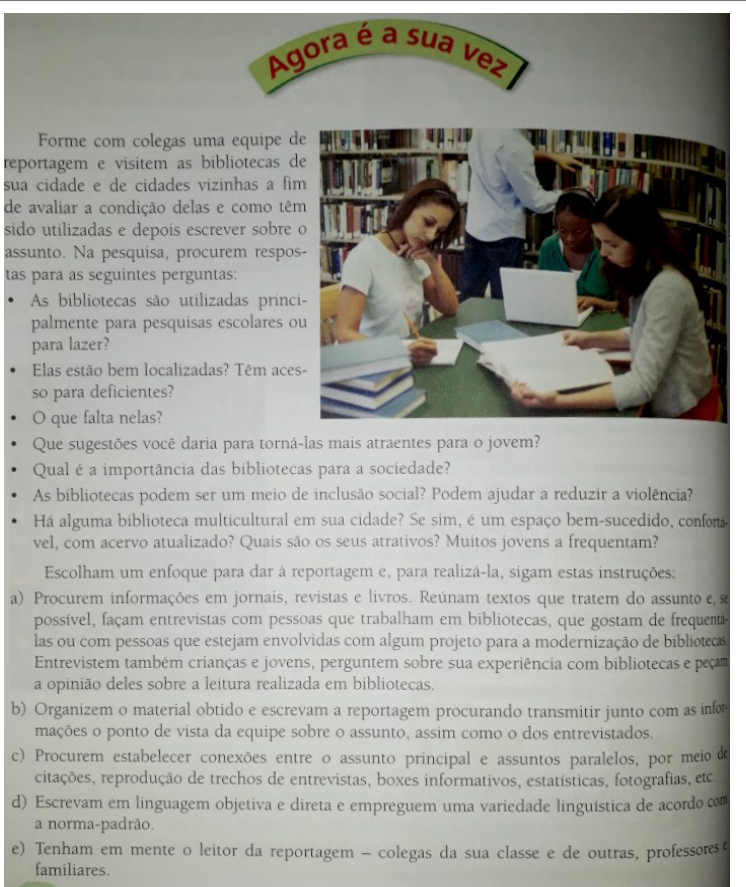 \\
\hline 1/2-Reportagem & 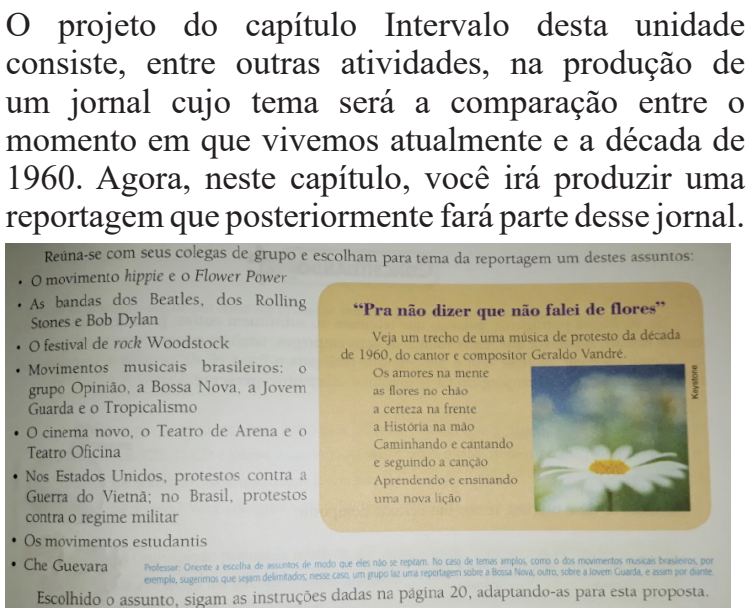 \\
\hline
\end{tabular}




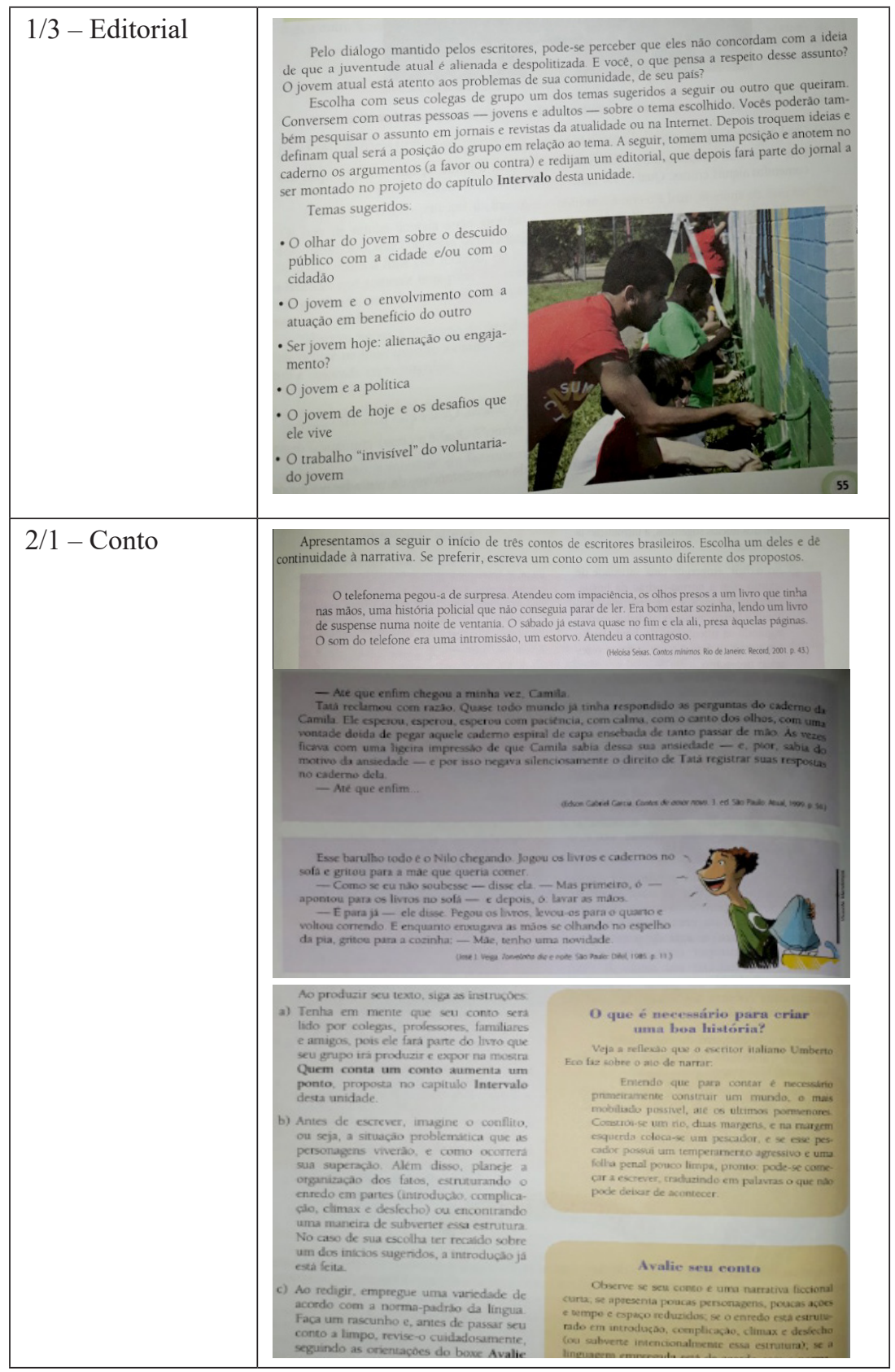

Signótica, GoiÂnia, v. 30, N. 2, p. 296-317, abr./jun. 2018 


\begin{tabular}{|c|c|}
\hline $2 / 2-$ Conto II & 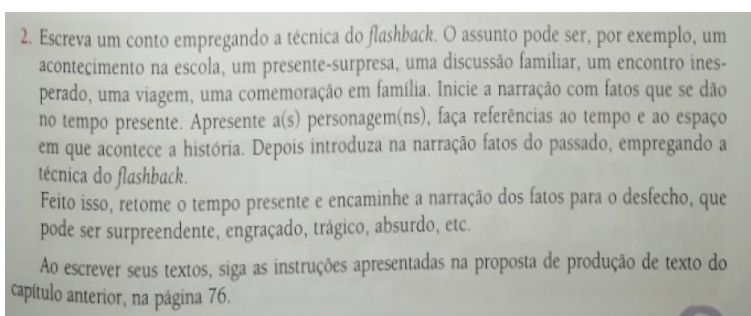 \\
\hline 2/3 - Conto III & $\begin{array}{l}\text { Neste caso, há o item Produção de texto, mas não existe } \\
\text { a seção Agora é sua vez, ou seja, não foi solicitada } \\
\text { uma produção textual. Há apenas comparações entre } \\
\text { contos, passando-se ao estudo de aspectos da língua. }\end{array}$ \\
\hline \multirow[t]{3}{*}{$\begin{array}{l}3 / 1-\text { Debate } \\
\text { regrado público }\end{array}$} & $\begin{array}{l}\text { Agora é a Sua } \\
\text { Com a orientaçảo do professor, participe com os colegas de um debate regrado sobre o tema: } \\
\text { Telerisaio: deformadora de costumes ou espelho de uma sociedade doente?. } \\
\text { Para ampliar as informaçóes que vocé tem sobre o assunto, leia o painel de textos a seguir. }\end{array}$ \\
\hline & Preparando e realizando o debate \\
\hline & 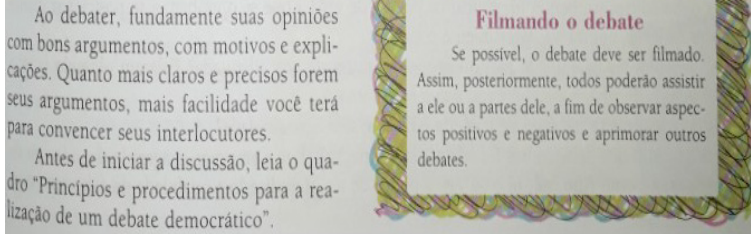 \\
\hline $\begin{array}{l}3 / 2 \text { - Debate } \\
\text { regrado público }\end{array}$ & 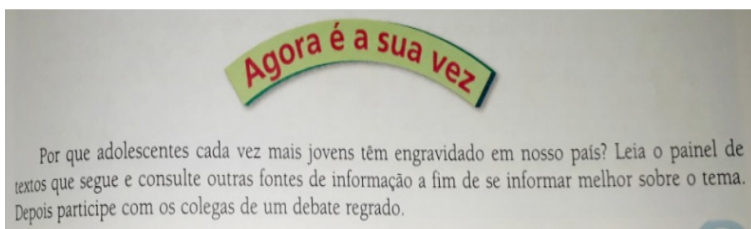 \\
\hline $\begin{array}{l}3 / 3-\text { Texto } \\
\text { dissertativo- } \\
\text { argumentativo }\end{array}$ & 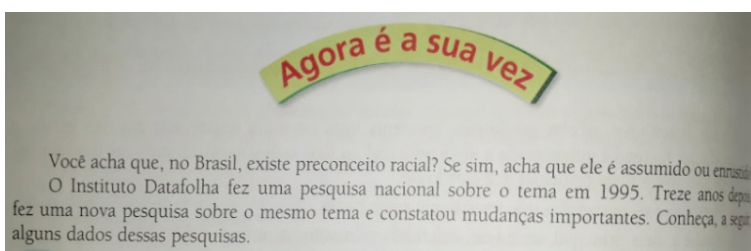 \\
\hline
\end{tabular}




\begin{tabular}{|c|c|}
\hline $\begin{array}{l}4 / 1-\text { Texto } \\
\text { dissertativo- } \\
\text { argumentativo: a } \\
\text { informatividade }\end{array}$ & $\begin{array}{l}\text { Toda vez que ouvimos falar em clonagem, deparamo-nos com questóes relacionadas com ciéncią, } \\
\text { saúde, ética, justiça e religião. } \\
\text { Por que o tema é tão debatido e tão controvertido? } \\
\text { A fim de se informar melhor sobre o assunto, leia o painel de textos a seguir. }\end{array}$ \\
\hline & 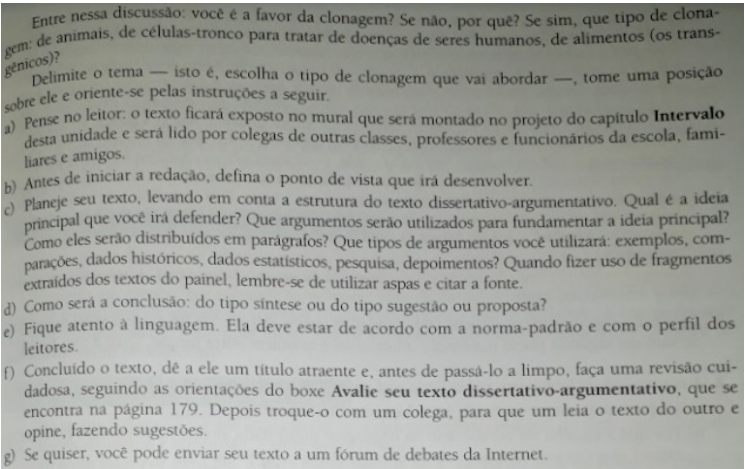 \\
\hline $\begin{array}{l}4 / 2-\text { Texto } \\
\text { dissertativo- } \\
\text { argumentativo: } \\
\text { a qualidade dos } \\
\text { argumentos }\end{array}$ & 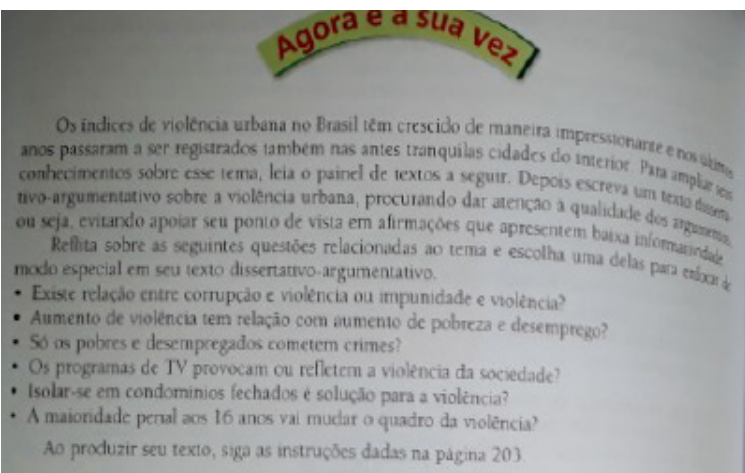 \\
\hline $\begin{array}{l}4 / 3-\text { Texto } \\
\text { dissertativo- } \\
\text { argumentativo: } \\
\text { continuidade e } \\
\text { progressão }\end{array}$ & 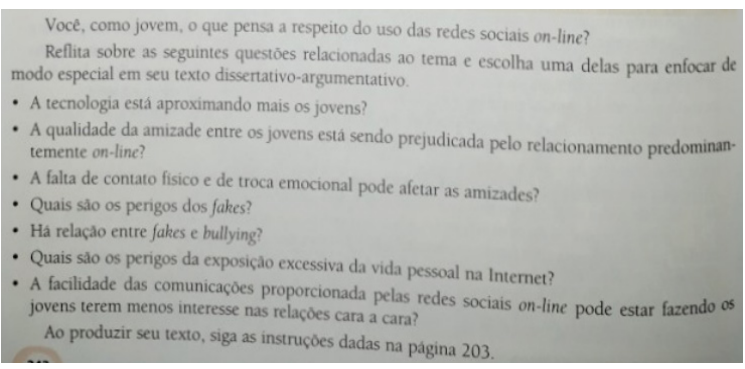 \\
\hline
\end{tabular}

Fonte: Elaborada com base no livro Português: Linguagens de Cereja e Magalhães (2012), volume IV, $9^{\circ}$.ano. 
A partir dos dados expostos, percebeu-se o que segue:

\subsection{UNIDADE 1}

Na proposta de produção do gênero reportagem sobre bibliotecas, presente no capítulo 1 , da unidade 1 , há uma vaga contextualização da situação de produção do gênero quando é proposto que o aluno leve em conta os supostos leitores da reportagem a ser escrita: "Tenham em mente o leitor da reportagem - colegas da sua classe e de outras, professores e familiares". Como a noção de endereçamento proposta por Bakhtin diz respeito à atitude que o locutor terá em relação ao interlocutor, a proposta, por conter poucos dados sobre o(s) suposto(s) leitor(es) do texto, não orienta suficientemente o estudante-escritor em relação a esses interlocutores e a seus lugares sociais, sendo que isso é entendido, de acordo com a referida teoria, como fundamental quando se solicita ao estudante que escreva; afinal, os interlocutores irão analisar informações presentes no texto de acordo com o gênero, a idade, o lugar social que ocupam, as condições culturais, entre outros elementos, assumindo atitude responsiva, conforme conceito bakhtiniano, frente ao que leram. Desse modo, como a escrita dessa reportagem desconsidera as características do provável leitor, pode haver um endereçamento inadequado, gerando, por exemplo, problemas como temática desenvolvida de forma que não interessa o público-alvo, uso de linguagem inadequada ao interlocutor, entre outros. Além disso, é mais difícil que o estudante revele uma posição frente à realidade sem explorá-la suficientemente.

No capítulo 2 da unidade 1, propõe-se a produção de uma reportagem a respeito da juventude brasileira dos anos 60. Como pode ser visto na imagem acima, recomenda-se seguir as instruções fornecidas na página 20 do livro, ou seja, constantes na proposta de produção de reportagem do capítulo 1 da unidade 1 , cabendo, nesse caso, a mesma análise realizada anteriormente, pois a noção de endereçamento está posta nas instruções do primeiro capítulo da primeira unidade. Diante disso, nas duas solicitações de escrita, embora haja uma breve caracterização do público-alvo ao qual a produção será dirigida, a descrição do interlocutor é insuficiente para contemplar a noção bakhtiniana de endereçamento. 
No capítulo 3 da unidade 1, solicita-se que os alunos "redijam um editorial, que depois fará parte do jornal a ser montado no projeto do capítulo Intervalo desta unidade" (CEREJA; MAGALHÃES, 2012, p. 55). Nesse caso, a única orientação que diz respeito ao endereçamento está implícita, pois não foi dito onde o jornal circulará e nem quem o lerá. Nesse caso, a descrição do interlocutor é insuficiente para contemplar a noção bakhtiniana de endereçamento. Assim, levando em conta a teoria de Bakhtin (2003) apresentada anteriormente, a palavra, utilizada na produção textual, não se efetiva como um elo entre os interactantes.

\subsection{UNIDADE 2}

Na proposta de produção do gênero conto do capítulo 1 da unidade 2 ocorre também uma especificação imprecisa dos leitores: "Tenha em mente que seu conto será lido por colegas, professores, familiares e amigos, pois ele fará parte do livro que seu grupo irá produzir e expor na mostra Quem conta um conto aumenta um ponto, [...]" (CEREJA; MAGALHÃES, 2012, p. 76). Basicamente, diferencia-se do contexto de produção da reportagem, porque o trabalho será exposto em uma mostra, dado que pode tornar a caracterização do interlocutor ainda mais vaga, por ele ter sido descrito de forma superficial.

Nesse sentido, segundo Bakhtin (2003), os outros, ou seja, aqueles a quem o enunciado elaborado se endereça, têm um papel ativo na construção do discurso. Nessa perspectiva, analisar atentamente o interlocutor permite perceber o nível de conhecimento que ele tem sobre o assunto, bem como suas inquietudes e pontos de vista relacionados ao tema. Desse modo, o fato de o livro não caracterizar suficientemente quem é o outro na proposta de produção do conto faz com que a concepção de endereçamento não seja contemplada. Essa mesma análise se aplica à produção do conto do capítulo 2 da unidade 2, a qual solicita seguir as instruções fornecidas na página 76 (capítulo 1 da unidade 2).

\subsection{UNIDADE 3}

No que se refere ao endereçamento da produção do gênero debate regrado público, presente nos capítulo 1 e 2 da unidade 3 , avaliou-se 
que não há indicação precisa de como o aluno pode analisar o perfil de seus interlocutores ("o texto deverá ser exposto no mural da classe e, portanto, lido por seus colegas"), a fim de construir argumentos que possam convencê-los. A proposta também poderia explorar contraargumentos que os colegas utilizariam em situação similar. Um cuidado nesse sentido contemplaria a noção de endereçamento, pois o locutor elabora seus argumentos a partir do conhecimento que o outro do discurso pode ter em relação ao tema. Assim, quais concepções sobre a televisão que o outro pode defender e que preconceitos apresenta? Que aspectos relacionados à televisão como deformadora de costumes ou como espelho de uma sociedade pode abordar? Essa caracterização seria interessante, porque determinaria a compreensão responsiva ativa que o interlocutor faria do colega locutor.

A proposta também poderia contemplar, por exemplo, o levantamento: dos conhecimentos que o outro do discurso teria em relação ao tema a partir do qual o locutor elabora seus argumentos; das concepções sobre a televisão que o outro poderia defender e dos preconceitos que poderia apresentar; de aspectos relacionados à televisão como deformadora de costumes ou como espelho de uma sociedade que ele pode abordar, etc. Essa caracterização, segundo os construtos apresentados, abrangeria a compreensão responsiva ativa que o interlocutor poderia fazer da fala do aluno/locutor. Enfim, a descrição do interlocutor é insuficiente para contemplar a noção bakhtiniana de endereçamento.

\subsection{UNIDADE 4}

Os capítulos 1 e o 2 da unidade 4 trabalham com o gênero texto dissertativo-argumentativo. Todos expõem o endereçamento da produção de forma semelhante, visto que os discursos produzidos serão, em todos os casos, expostos no mural, indicando leitura breve e superficial do interlocutor ("pense no leitor: o texto ficará exposto no mural que será montado no projeto do capítulo Intervalo desta unidade e será lido por colegas de outras classes, professores e funcionários da escola, familiares e amigos"). Os interlocutores também não são caracterizados de forma clara no que se refere à questão social e cultural. 
Ademais, nos capítulos 2 e 3 da unidade 4, o aluno/escritor consegue ter informações sobre a temática da produção, mas precisa retomar orientações contidas no capítulo 1 da unidade 4 para elaborar seu texto.

Nesse sentido, em função do modo como o outro foi caracterizado, as propostas dessa unidade não contemplam a noção de endereçamento de Bakhtin. Dessa forma, o estudante que escreve não consegue, de acordo com o referido Bakhtin (2003), perceber a "vontade discursiva" do interlocutor. A consequência dessa falta de direcionamento é a possibilidade de a produção escrita realizada, saindo dos muros da escola e chegando à comunidade, ser lida por um interlocutor e este não conseguir perceber o "tom conclusivo" presente no discurso, detalhe importante ao refletir sobre o fato de que as propostas eram argumentativas. Para Bakhtin, quando essa "conclusibilidade" fica prejudicada, pode não haver uma "atitude responsiva" por parte do leitor, que poderia concordar ou discordar com as teses defendidas e criar réplicas.

Diante disso, a análise do material didático permitiu observar que os autores têm preocupação de caracterizar o interlocutor - alunos da escola, colegas de classe, professores e pais, por exemplo. Entretanto, mesmo defendendo a perspectiva enunciativa, o manual mantém artificialidade nas produções sugeridas, não propiciando, segundo análise a partir das noções expostas de Bakhtin (2003), diálogo efetivo e necessário.

\section{CONSIDERAÇÕES FINAIS}

Se o diálogo pressupõe um interlocutor, ou seja, o outro no discurso, entende-se que o livro didático, para atingir seu objetivo favorecer a aprendizagem dos estudantes por meio de situações de ensino -, deveria apresentar condições que simulem situação discursiva e enunciativa na qual fique claro quem é o interlocutor do estudante/ escritor. Quando esse outro do discurso é negligenciado na produção de gêneros discursivos, a escrita pode tornar-se vazia de sentido, em virtude de parecer artificial, ou seja, realizada pelo aluno, provavelmente, para atender à demanda do exercício e receber avaliação positiva.

No conjunto das atividades de produção de gêneros discursivos do manual didático analisado, percebeu-se que a noção bakhtiniana 
de endereçamento não foi contemplada. Quando um interlocutor era simulado, mostrava-se de modo genérico. A partir disso, questionase se, de fato, os apontados nas propostas são os interactantes reais dos estudantes, os quais, em seu dia a dia, comunicam-se por escrito com variados públicos, em diversos suportes, realizando, inclusive, interações por meio das novas tecnologias. Se não o são, pode-se notar a artificialização do discurso. Isso pode demonstrar certa fragilidade do livro didático analisado, convocando o professor a realizar a mediação, elaborando, inclusive, outras propostas de escrita ou caracterizando melhor o interlocutor.

Para evitar esse problema, as propostas didáticas para produção escrita poderiam construir situações enunciativas apresentando interlocutores efetivos, como os do círculo social e das atividades diárias do estudante, gerando mais familiaridade e, assim, provocando a escrita. Os interlocutores não estão restritos ao ambiente escolar. Desse modo, seria importante propiciar situações enunciativas capazes de permitir ao aluno produzir seu texto levando em conta as diferentes necessidades comunicativas do dia a dia, nas mais variadas esferas, não somente naquelas nas quais a escola está inserida.

Assim, sugere-se explorar características como a condição social e cultural dos interlocutores, o sexo, a idade, as posições políticas ou ideológicas, entre outras possibilidades. Parece ser importante ainda alertar o aluno a respeito da repercussão - réplicas e reações - que sua escrita pode gerar no meio social, dependendo de onde é produzida e exposta. Enfim, respeitando a natureza do processo enunciativo, as propostas de produção textual precisam, efetivamente, assumir postura dialógica.

ADRESSING IN THE PROPOSITIONS OF TEXT PRODUCTION IN ELEMENTARY EDUCATION TEXTBOOK

\section{ABSTRACT}

The present study aims to analyze how text production proposals presented in elementary schools textbooks guide the student in terms of interlocution, observing if the material worries in characterize the likely interlocutor in the text to be produced by the student. The dialogic theory of Bakhtin is taken as a base, adopting a Enunciative-discursive perspective of language. Text 
production proposals in the collection Português: Linguagens, by Willian Roberto Cereja and Thereza Cochar Magalhães were analyzed. From the analyzed corpus, it was observed that the proposals do not present a detailed characterization of the possible interlocutor, not fully contemplating the Bakhtinian notion of addressing. Thus, because they do not explain who the other of the discourse is, the writing produced by the student may, in addition to becoming artificial, not favor the establishment of an active and effective dialogue between the interactants.

KEYWORDS: Addressing, text production, textbook.

\section{DIRECCIONAMIENTO EN LAS PROPUESTAS DE PRODUCCIÓN TEXTUAL EN LIBRO DIDÁCTICO DE LA ENSEÑANZA FUNDAMENTAL}

\section{RESUMEN}

El presente estudio tiene por objetivo analizar cómo propuestas de producción textual vehiculadas en libro didáctico de la Enseñanza Fundamental sitúan al alumno en términos de interlocución, observando si ese material presenta la preocupación de caracterizar al probable interlocutor del texto a ser producido por el alumno. Se toma como base la teoría dialógica de Bakhtin, adoptándose perspectiva enunciativo-discursiva de lenguaje. Se optó por el análisis de propuestas de producción textual presentes en la colección Português: Linguagens, dos autores Willian Roberto Cereja y Thereza Cochar Magalhães. A partir del corpus analizado, se observó que las referidas propuestas no presentan una caracterización detallada del posible interlocutor, no contemplando plenamente la noción bakhtiniana de direccionamiento. Así, en función de ellas no explicitar quién es el otro del discurso, la escritura producida por el estudiante puede, además de tornarse artificial, no favorecer el establecimiento de un activo y efectivo diálogo entre los interactivos.

Palabras ClaVE: Direccionamiento, producción textual, libro didáctico.

\section{NOTAS}

1. Esse indicador resulta de pesquisa realizada pelo Instituto Paulo Montenegro em parceria com a Organização Ação Educativa e a IBOPE Inteligência. 
2. A expressão Círculo de Bakhtin é usada neste trabalho porque alguns como interação verbal, enunciado concreto, signo ideológico e dialogismo são produtos de reflexão do grupo que tinha participação de diversos intelectuais como V. N. Volochínov (1895-1936), P. Medvedev (1892-1938), I. Kanaev (1893-1983), M. Kagan (1889-1934), L. Pumpianskii (1891-1940), M. Yudina (1899-1970), K. Vaguinov (1899-1934), I. Sollertinski (1902-1944), B. Zubakin (1894-1937) (BRAIT; CAMPOS, 2009, p. 17).

3. Conforme prefácio de Roman Jakobson, a primeira edição da obra, em 1929-1930, era assinada por V. N. Volochínov.

4. A obra "A estética da criação verbal" foi produzida nos anos de 1920-1924 e foi publicada em russo em 1979 (BOUKHARAEVA, 1997, p. 76)

5. A enunciação é definida por Bakhtin (1981, p. 112) como "produto da interação de dois indivíduos socialmente organizados".

\section{REFERÊNCIAS}

BRASIL. Decreto n ${ }^{\circ}$ 9.099, de 18 de julho de 2017. Dispõe sobre o Programa Nacional do Livro e do Material Didático. Disponível em: <http://www. planalto.gov.br/ccivil_03/_ato2015-2018/2017/decreto/D9099.htm>. Acesso em: 15 dez. 2017.

BAKHTIN, Mikhail. Estética da criação verbal. Tradução: Paulo Bezerra. 4. ed. São Paulo: Martins Fontes, 2003.

BAKHTIN, Mikhail (Volochínov). Marxismo e filosofia da linguagem. Tradução: Michel Larud e Yara Frateschi Vieira. 2. ed. São Paulo: Hucitec, 1981.

BRAIT, Beth; MELO, Rosineide de. Enunciado/ enunciado concreto/ enunciação. In: BRAIT, Beth (Org.). Bakhtin: conceitos chaves. São Paulo: Contexto, 2005.

. CAMPOS, Maria Inês Batista. Da Rússia czarista à web. In: BRAIT, B. (Org.). Bakhtin e o Círculo. São Paulo: Contexto, 2009.

BOUKHARAEVA, Louiza Mansurovna. Começando o diálogo com Mikhail M. Bakhtin. Ijuí, RS: Ed.UNIJUÍ, 1997.

CEREJA, William Roberto; MAGALHÃES, Thereza Cochar. Português: linguagens. $9^{\circ}$ ano: língua portuguesa. 7. ed. São Paulo: Saraiva, 2012.

FLORES, Valdir do Nascimento et al (Org.). Dicionário de linguística da enunciação. São Paulo: Contexto, 2009. 
INSTITUTO PAULO MONTENEGRO - IPM. INAF: Leitura e Escrita - 2011 - 2012. Relatório on-line. Disponível em: <http://www.ipm.org.br/download/ inf_resultados_inaf2011_ver_final_diagramado_2.pdf $>$. Acesso em: 29 abr. 2014.

MAGALHÃES, Fernanda Pizarro. Gêneros discursivos da esfera empresarial no ensino da Educação Profissional: reflexões, análises e possibilidades. 2011. 359f. Tese (Doutorado em Linguística Aplicada) - Universidade Católica de Pelotas, Pelotas, RS, 2011.

MARCUSCHI, Luiz Antônio. Gêneros textuais: definição e funcionalidade. In: DIONISIO, Angela Paiva; MACHADO, Anna Rachel; BEZERRA, Maria Auxiliadora (Org.). Gêneros textuais e ensino. 2. ed. Rio de Janeiro: Lucerna, 2003.

REINALDO, Maria Augusta de Macedo. Saberes sobre produção de texto e avaliação de material didático na formação continuada. Trabalhos em Linguística Aplicada, v. 45, n. 2, p. 271-292, dez. 2006.

Submetido em 28 de agosto de 2017.

Aceito em 04 de dezembro de 2017.

Publicado em 23 de abril de 2018. 